\title{
Analysis of potential advanced thorium based fuel for EPR reactor
}

\author{
Marcin Szuta ${ }^{1}$ \\ National Centre for Nuclear Research NCBJ \\ 05-400 Otwock-Świerk, Polandy \\ E-mail: mszuta@cyf.gov.pl
}

\section{Andrzej Wojciechowski}

National Centre for Nuclear Research NCBJ

05-400 Otwock-Świerk, Polandy

E-mail:andrzej@cyf.gov.pl

As thorium based fuels have benefits in terms of radio-toxicity there are however challenges in terms of reprocessing the spent thorium based fuel. The database and experience of thorium fuels and thorium fuel cycles are very limited, as compared to $\mathrm{UO}_{2}$ and $(\mathrm{U}, \mathrm{Pu}) \mathrm{O}_{2}$ fuels, and need to be augmented before large investments are made for commercial utilization of thorium fuels and fuel cycles.

That is why, as the first step of studying the thorium application feasibility, once through thorium based fuel cycle analysis for energy production and radioactive waste transmutation was undertaken, which does not require the technically difficult reprocessing of the spent fuel.

The idea is to analyze the thorium based fuel application in the open cycle feasibility study in the existing light water reactors with minimal modifications in order to exploit them.

Preliminary analysis of thorium based fuel application in the EPR reactor have shown that once through thorium fuel cycle can be reached with difficulty. It is inferred that the ${ }^{233} \mathrm{U}$ concentration tends to saturation value which does not depend on power density while the kinetics of reaching the saturation value depends on it.

Monte Carlo methodology calculations for the contribution to the analysis of thorium based fuel application in the EPR reactor and in the accelerated driven systems (ADS) were used.

XXI International Baldin Seminar on High Energy Physics Problems

JINR, Dubna, Russia

September 10-15, 201

1

Speaker Marcin Szuta 


\section{Introduction}

Assessment of radioactive waste generated in the energetic reactors.

The energetic reactor of $1000 \mathrm{MW}_{\mathrm{e}}$ electric nominal power generates about 10 tons per year of the spent fuel. Using the data given in Fig. 1 [1] the quantitative isotopic composition of this fuel is as follows: $9430 \mathrm{~kg} \mathrm{U}-238,80 \mathrm{~kg}$ U-235, $350 \mathrm{~kg}$ of fission products, $89 \mathrm{~kg}$ of different isotopes of plutonium and $46 \mathrm{~kg} \mathrm{U}-236,5 \mathrm{~kg} \mathrm{~Np}-237,1.2 \mathrm{~kg}$ of Am-243 and $0.4 \mathrm{~kg} \mathrm{Cm}-244$. As these data correspond to the fuel burn-up of about $40 \mathrm{GWD} / \mathrm{tU}$ we can expect that the amount of fission products and actinides increases by a coefficient 1.5 .

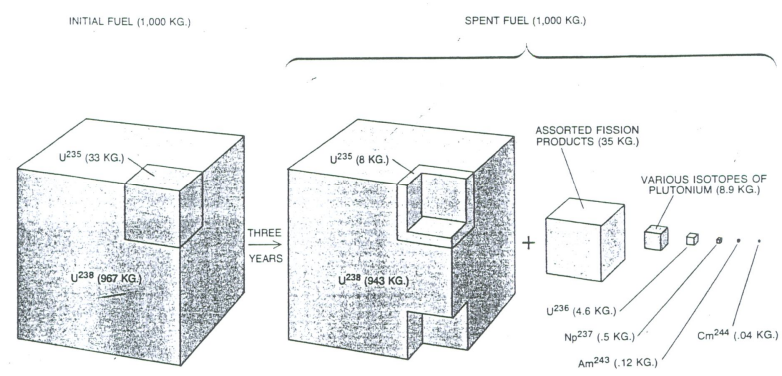

Fig. 1. Balance of fission products and actinides in one tone of uranium fuel enriched to $3.3 \%{ }^{235} \mathrm{U}$ after three years of exploitation in the energetic reactor [1].

The above estimate of isotopic quantities in the spent fuel after prolonged cooling brings the following list of the radio-nuclides with half-life of more than 10 years [2].

The main contributors to the long-term radiation hazard of spent nuclear fuel (SNF) are radio-nuclides with half-life of more than 10 years [2] - actinides (plutonium, americium, curium) and some fission products $\left({ }^{129} \mathrm{I},{ }^{99} \mathrm{Tc}\right.$, etc. $)$

The potential radio-toxicity of fission products can be neglected after 250 years. However the potential radio-toxicity of actinides remain yet high after several million years [3].

An intense thermal flux provides rapid and efficient transmutation of the fission products [4]. Comparison of ${ }^{99} \mathrm{Tc},{ }^{129} \mathrm{I},{ }^{90} \mathrm{Sr}$ and ${ }^{137} \mathrm{Cs}$ cross sections for transmutation in the thermal and fast neutron energy regions show that at thermal energies, fission product transmutation cross sections are uniformly about an order of magnitude higher than at fast neutron energies.

The long leaving iodine ${ }^{129} \mathrm{I}$ after neutron capturing becomes an iodine ${ }^{130} \mathrm{I}$ which decays to the stable xenon ${ }^{130} \mathrm{Xe}$ according to the reaction [5]:

The problem is that the actinide waste, which consists of neptunium and higher atomic number elements except plutonium, is thought not to transmute well in a thermal flux of the typical commercial power reactor (3000 MW ) which has thermal neutron flux of approximately $10^{14} \mathrm{n} / \mathrm{cm}^{2} \mathrm{~s}$

It is also known that the high flux thermal neutron environment $\left(\geq 10^{16} \mathrm{n} / \mathrm{cm}^{2} \cdot \mathrm{s}\right)$ is expected as the best way for the transmutation of most of the radioactive waste to stable or short-lived nuclides and for increasing the probability for fission such actinides as ${ }^{237} \mathrm{~Np}$ and ${ }^{238} \mathrm{~Np}$. As an example Fig. 2 shows an effective neptunium cross section for fission in function of an intense thermal neutron flux [1]. Note that there is not a sharp threshold, but that the 
advantage of $10^{16} \mathrm{n} / \mathrm{cm}^{2} \mathrm{~s}$ is very significant (about $35 \mathrm{~b}$ ). For comparison, the fission cross section of ${ }^{237} \mathrm{~Np}$ in a fast neutron is about $1.5-2$ barn [4].

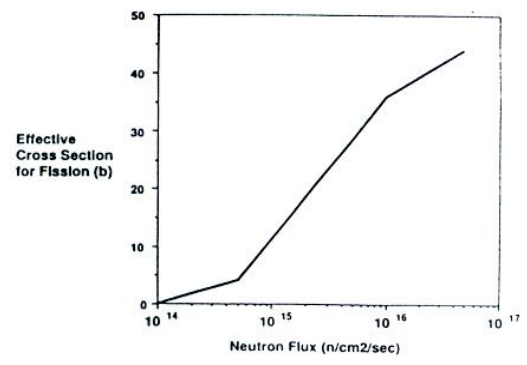

Fig. 2. Neptunium fission in an intense thermal neutron flux [4].

Analysis of possible ways of reduction of radioactive wastes by transmutation of radioactive long-lived fission products such as ${ }^{99} \mathrm{Tc},{ }^{129} \mathrm{I}$ and ${ }^{135} \mathrm{Cs}$ and by burning up of transuranic nuclides implies that the reactor core should consist of three zones with fast, epithermal and thermal neutron spectra.. High flux thermal neutron environment $\left(\geq 10^{16}\right.$ $\mathrm{n} / \mathrm{cm}^{3} \cdot \mathrm{s}$ ) is expected as the best way for the transmutation of most of the radioactive waste to stable or short-lived nuclides and for increasing the probability for fission such actinides as ${ }^{237} \mathrm{~Np}$ and ${ }^{238} \mathrm{~Np}$.

Since we are not able to construct such a reactor core with the three zones (with fast, epithermal and thermal neutron spectra) and we are not able to reach such an intense thermal neutron flux $\left(\geq 10^{16} \mathrm{n} / \mathrm{cm}^{3} \cdot \mathrm{s}\right)$ in terms of technical feasibility and in view of the inefficiency of actinides incineration for a low intensity thermal neutron flux, we focus our attention on the thorium-uranium fuel cycle as a prophylactic (prophylaxis) way of energy production where the radio-toxicity of the wastes is about three orders of magnitude smaller than in the case of classical PWR [6] reactors as illustrated in Figure 3. This figure shows clearly the advantage of the thorium-uranium cycle.

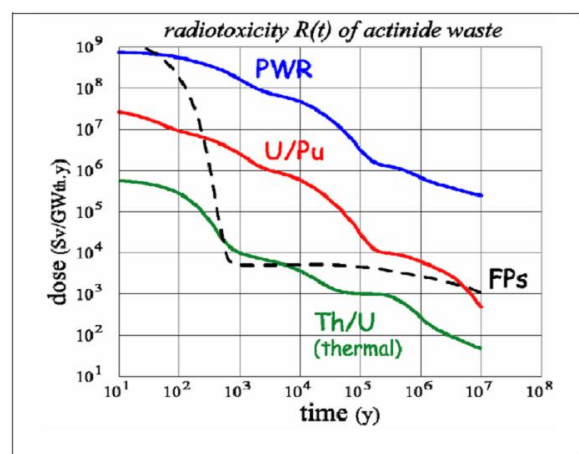

Fig. 3. Radio-toxicity for various cycles [6].

Moreover this is supported by the fact that in the past decade there has been a renewal of interest in studying the feasibility of thorium-based fuel reactors as a potential advanced fuel for Generation IV nuclear energy systems producing fewer minor actinides than in uranium basedfuel. 
Conversion of ${ }^{232} \mathrm{Th}$ to ${ }^{233} \mathrm{U}$ is more efficient than that of ${ }^{238} \mathrm{U}$ to ${ }^{239} \mathrm{Pu}$ in thermal neutron spectrum though the resonance integral of ${ }^{232} \mathrm{Th}$ is one third of that of ${ }^{238} \mathrm{U}$ [7].

The ${ }^{232} \mathrm{Th}-{ }^{233} \mathrm{U}$ fuel cycle let us obtain breeding of fissile atoms (material) both in fast, epithermal and thermal neutron spectra. The thermal breeder reactor can be constructed is clearly seen in Fig. 4 [8].

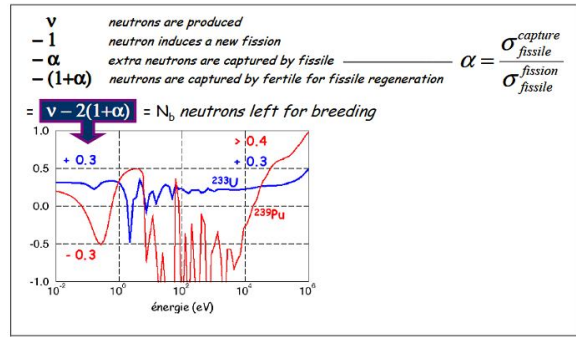

Fig. 4. Available neutrons for breeding both for ${ }^{233} \mathrm{U}$ and ${ }^{239} \mathrm{Pu}[8]$.

The authors [8] underline that as long as the available neutron numbers for breeding $\left(\mathrm{N}_{\mathrm{b}}\right)$ is always slightly larger than 0 , breeding is possible. This is the case for the whole neutron energy spectrum for uranium 233 where $\mathrm{N}_{\mathrm{b}}$ is always equal 0.3.

However the number of neutrons available for breeding $(\mathrm{Nb})$ presented in paper [6] is equal to about 0.1 (see Fig. 5). In the Fig. 5 the breeding feasibility for different fuel cycles is considered. As Figure 5 illustrates, while the uranium 238-plutonium 239 fuel cycle requires fast neutrons to be sustainable, the thorium 232-uranium 233 fuel cycle is sustainable with either thermal neutrons or fast neutrons.

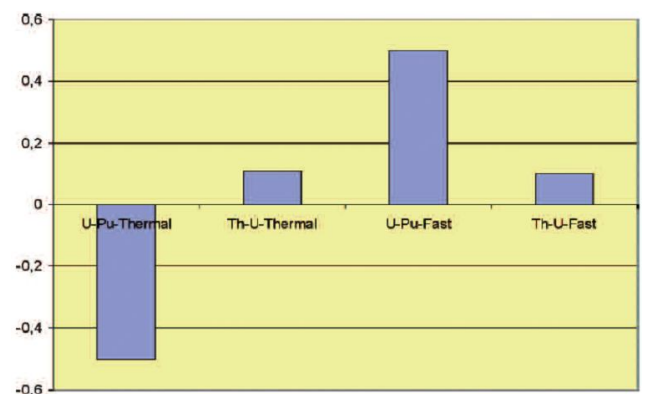

Fig. 5. Number of neutrons available for breeding $(\mathrm{Nb})$ in the uranium-plutonium and the thorium-uranium cycles with thermal and fast neutron spectra. Breeding is impossible for negative values of $(\mathrm{Nb})[6]$.

As thorium based fuels have benefits in terms of radio-toxicity there are however challenges in terms of reprocessing the spent thorium based fuel. The database and experience of thorium fuels and thorium fuel cycles are very limited, as compared to $\mathrm{UO}_{2}$ and $(\mathrm{U}, \mathrm{Pu}) \mathrm{O}_{2}$ fuels, and need to be augmented before large investments are made for commercial utilization of thorium fuels and fuel cycles [7].

That is why, as the first step of studying the thorium application feasibility, once through thorium based fuel cycle analysis for energy production and radioactive waste transmutation was undertaken, which does not require the technically difficult reprocessing of the spent fuel.

The idea is to perform the thorium based fuel application in the open cycle feasibility study in the existing light water reactors with minimum modifications in order to exploit them. 


\section{Preliminary analysis of thorium based fuel application in the EPR reactor.}

The thorium cycle has advantages as compared to the uranium cycle as follows: thorium cycle decreases production of minor actinides (MA), thorium has a fairly large abundance ratio in natural resources, too.

In many institutes the possibility of using thorium [9-16] in reactors was investigated. Some calculation results of thorium based fuel application in the EPR reactor are presented in the work [16].

The main aim of this work is to show dependence of thorium burn-up in different places of reactor core. It is needed to determine optimal conditions of U-333 productions (position in reactor core and burning period of time). To investigate this problem we used European Pressurized Reactor EPR[16-18].

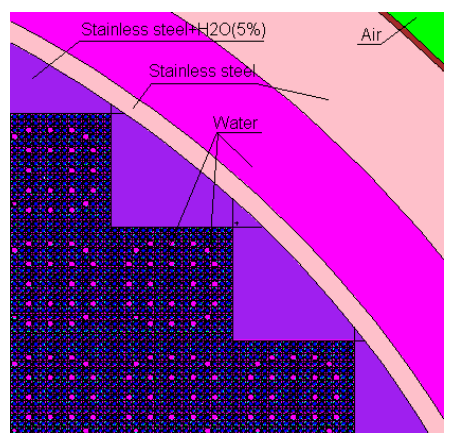

Fig. 6. Vertical cross section of EPR core fragment presenting several $\mathrm{UO}_{2}$ fuel assemblies neighboring the reflector (stainless steel $+\mathrm{H}_{2} \mathrm{O}(5 \%)$ ).

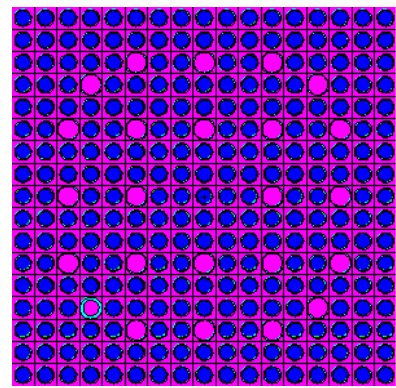

Fig. 6a. Vertical cross section of the schematic diagram of the EPR fuel assembly - blue color means fuel rods with $\mathrm{UO}_{2}$ of $2.25 \mathrm{wt} \%{ }^{235} \mathrm{U}$ enrichment, pink color means water.

In Fig. 6 and Fig. 6a are presented the vertical cross sections of EPR core fragment and the EPR fuel assembly.

Applying the Monte Carlo methodology (MCNPX 2,6) we have calculated the neutron multiplication factor $k_{\text {eff }}$ in function of burn-up for the reactor core loaded with 241 uranium fuel assemblies (maximal amount) as in Fig. 6 exploited in constant (fixed) power of 5000 $\mathrm{MW}_{\text {th }}$. Burn-up in the abscissa axis denotes the average burn-up. This calculation presented in Fig. 7 is performed in order to find a reference curve in further simulations. 


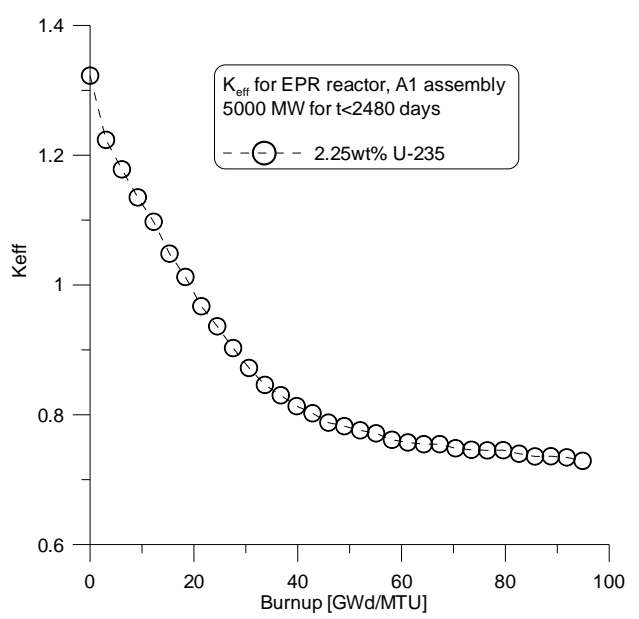

Fig. 7. Neutron multiplication factor versus burn-up for the EPR reactor core as in Fig. 6.

We have expected that a peripheral part of the reactor core is the best location of thorium dioxide rods to convert the fertile thorium ${ }^{232} \mathrm{Th}$ into fissile uranium ${ }^{233} \mathrm{U}$. That is why we performed computer simulation for the configuration (189 uranium and 52 thorium assemblies) presented in Fig. 8 and Fig. 8a and calculated the neutron multiplication factor $\mathrm{k}_{\mathrm{eff}}$ in function of irradiation time for constant power of $5000 \mathrm{MW}_{\text {th }}$ and compared it with the $\mathrm{k}_{\mathrm{eff}}$ for solely 189 uranium fuel assemblies. Variation of the $\mathrm{k}_{\mathrm{eff}}$ in function of time (burn-up) for the two core versions are presented in Fig. 9. It is clearly seen that impact of the peripheral thorium fuel element assemblies on the neutron multiplication factor is insignificantly small for the zero burn-up. The difference between the $\mathrm{k}_{\mathrm{eff}}$ of the two curves for higher burn-ups is a measuring instrument of fresh fuel assembly approximate quantity necessary to compensate the difference, what in turn let us to make assessment of the thorium based fuel production cost. We are conscious that the thorium is a poison for the reactor core by strong neutron absorption. From the other side during the reactor operation the loaded over-criticality is compensated by the shim rods which absorb the neutrons. These neutrons however are lost while the neutrons absorbed by the fertile thorium dioxide convert it into thorium based fuel. This of course marks down the cost.

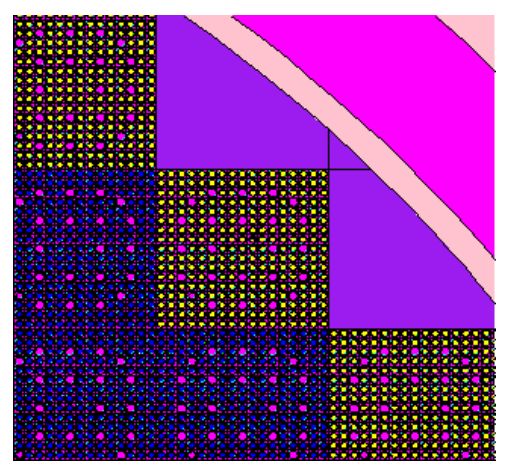

Fig. 8. Location of fuel assemblies in the EPR core: peripheral assemblies (52) neighboring the reflector $-\mathrm{ThO}_{2}$, remaining assemblies (189) $-\mathrm{UO}_{2}$. 


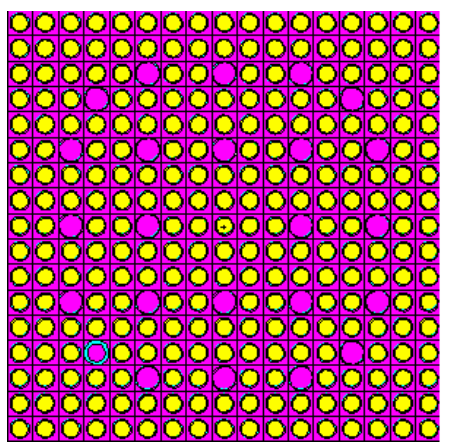

Fig. 8a. Fig. Vertical cross section of the schematic diagram of the EPR fuel assembly yellow color means fuel rods with $\mathrm{ThO}_{2}$, pink color means water.

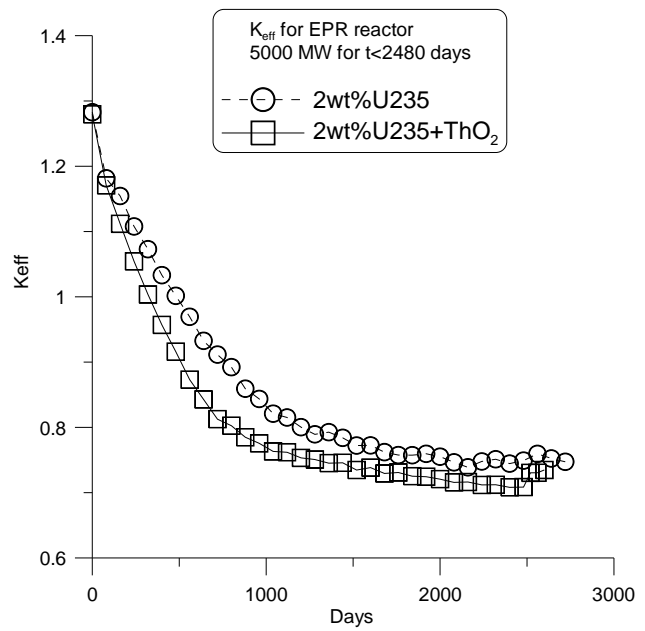

Fig. 9. Variation of $\mathrm{k}_{\mathrm{eff}}$ in function of irradiation time for the core configurations presented in Fig. 8 and the configuration when solely the uranium assemblies (189) are exploited on thermal power $5000 \mathrm{MW}_{\text {th }}$.

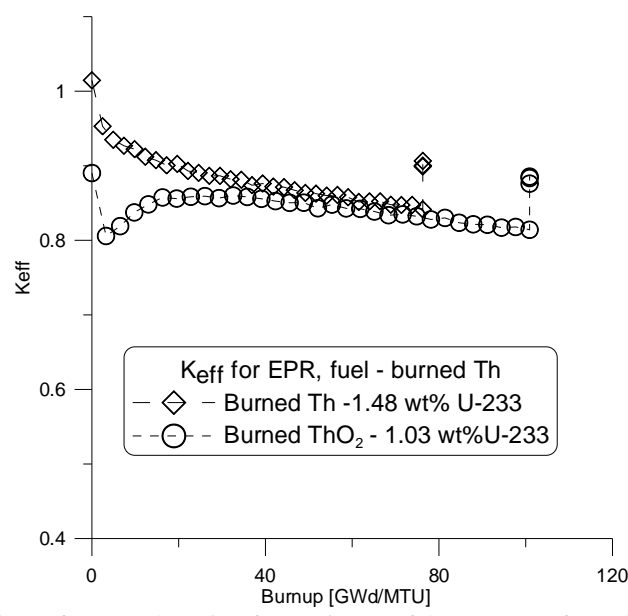

Fig. 10. Neutron multiplication factor $\mathrm{k}_{\mathrm{eff}}$ in function of burn-up for thorium fuel assemblies with $1.03 \mathrm{wt} \%$ and for $1.48 \mathrm{wt} \%{ }^{233} \mathrm{U}$ concentration of EPR reactor core exploited on the 5

$\mathrm{GW}_{\text {th }}$ power. 
Assuming that all the 241 thorium assemblies with $1.03 \mathrm{wt} \%$ concentration of uranium ${ }^{233} \mathrm{U}$ were loaded into EPR reactor core, we performed computer simulation of neutron multiplication factor $\mathrm{k}_{\mathrm{eff}}$ in function of burn-up for the $5 \mathrm{GW}_{\text {th }}$ power and compared it with the same simulation but for the uranium ${ }^{233} \mathrm{U}$ concentration equal to $1.48 \mathrm{wt} \%$ (see Fig. 10). We expect that the initial uranium ${ }^{233} \mathrm{U}$ concentration once is above and once is below the saturation concentration what explains the different shapes of these two curves. In the beginning of the burning process the U-233 concentration sharply decreases in both cases because the U-233 is not being produced due to the fact that the Pa-233 just started to appear. The half-life of Pa-233 totals about 27 days. Therefore the production of U-233 will appear with a delay. In case of a higher initial uranium ${ }^{233} \mathrm{U}$ concentration level $(1.48 \mathrm{wt} \%)$, the U-233 concentration tends monotonically to a saturation value. Whereas, in case of a lower initial uranium ${ }^{233} \mathrm{U}$ concentration level (1.03 wt $\%)$, the U-233 concentration at the beginning decreases and then increases again to the saturation value. The saturation value of ${ }^{233} \mathrm{U}$ concentration will be considered later.

In order to clarify the different shapes of neutron multiplication factor $k_{\text {eff }}$ presented in Fig. 10 and to investigate the uranium ${ }^{233} \mathrm{U}$ concentration dependence on fission rate and time of irradiation we assumed that the EPR fuel rod is filled with $\mathrm{UO}_{2}$ and $\mathrm{ThO}_{2}$ forming in the reactor core several fuel layers alternately located. Symmetrically from the fuel rod center, five thorium dioxide layers $20 \mathrm{~cm}$ thick are located (distributed) in the following ranges $30-50 \mathrm{~cm}, 70-90 \mathrm{~cm}$, $110-130 \mathrm{~cm}, 150-170 \mathrm{~cm}, 190-210 \mathrm{~cm}$. The remaining ranges are filled with enriched $2.25 \mathrm{wt} \%$ uranium dioxide (see fig.11). This kind of fuel rod arrangement is technically feasible.

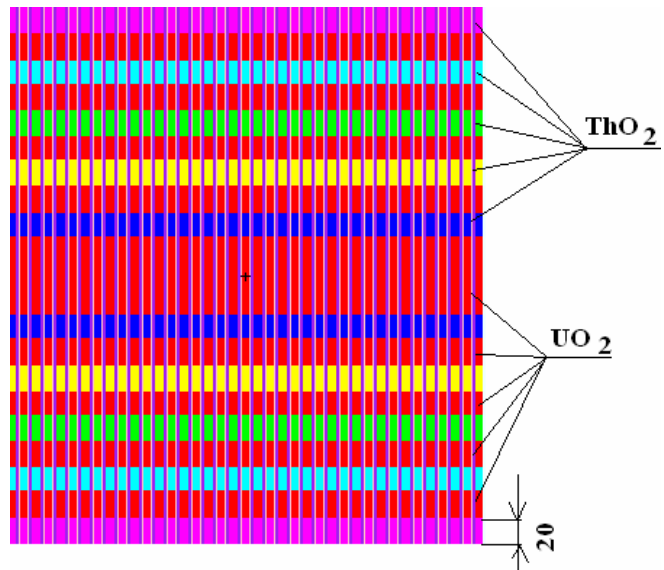

Fig. 11. Longitudinal cross section of EPR core. Different size fuel layers in reactor core.

Color red means $\mathrm{UO}_{2}$, Colors: blue, yellow, green, white blue, pink means $\mathrm{ThO}_{2}$

"Ab initio" calculations compared with the experimental data show that the lattice constants in the $\mathrm{Th}_{1-x} \mathrm{U}_{x} \mathrm{O}_{2}$ compound decrease linearly with increasing mole ratio $x$ what means that the uranium dioxide lattice constants are smaller than the thorium dioxide lattice constants (see Fig. 12) . This leads to the conclusion that the uranium dioxide and thorium dioxide-based fuel pellets can be in different proportions and alternately located in the fuel rod because U-233 increase in the thorium pellet causes a decrease its volume what, in turn do not generate stresses between the rod clad [19]. 


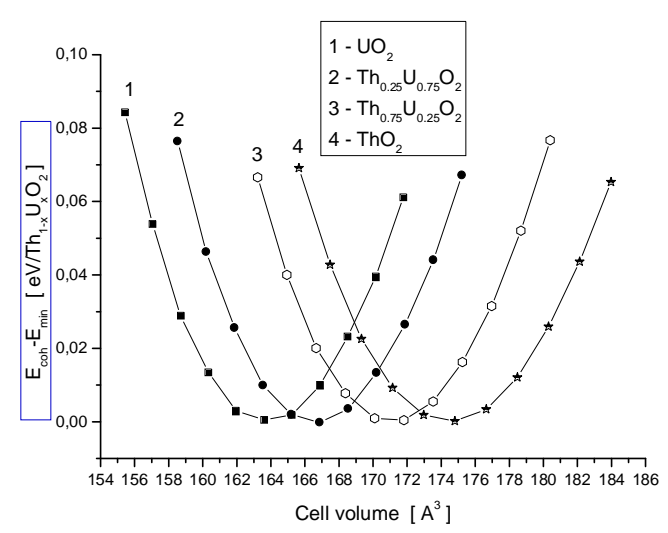

Fig. 12. Variation of the cohesive energy with cell volume for $\mathrm{Th}_{1-x} \mathrm{U}_{x} \mathrm{O}_{2}$ [19].

The MCNPX 2.6.0 code [20] was used to make Monte Carlo simulation of thorium dioxide based fuel behavior. The average error of the presented calculation results is about 1 $-2 \%$.

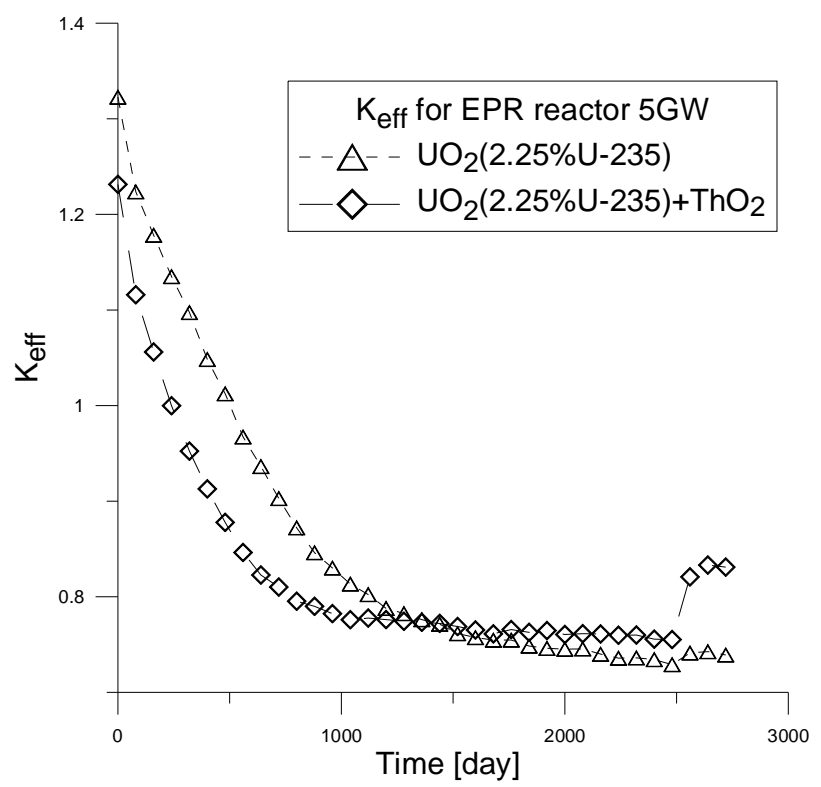

Fig. 13. Comparison of $\mathrm{k}_{\text {eff }}$ for $\mathrm{EPR}$ reactor core loaded with $\mathrm{UO}_{2}(2.25 \% \mathrm{U}-235)$ solely and with $\mathrm{ThO}_{2}+\mathrm{UO}_{2}$ as described in Fig. 11.

Fig. 13 shows comparison of $\mathrm{k}_{\text {eff }}$ for reactor core loaded with $\mathrm{UO}_{2}(2.25 \% \mathrm{U}-235)$ solely and with $\mathrm{ThO}_{2}+\mathrm{UO}_{2}$ as described above (see fig. 11). This comparison shows that using the $\mathrm{ThO}_{2}$ $+\mathrm{UO}_{2}$ fuel, the keff decreases about 0.1 from 1.31 to 1.21 at the beginning of exploitation. The applied thorium is a poison for the reactor core by strong neutron absorption. From the other side during the reactor operation the loaded over-criticality is compensated by the shim rods which absorb the neutrons. These neutrons however are lost while the neutrons absorbed by the fertile thorium dioxide convert it into thorium based fuel. So the thorium rods can play role of the shim rods. Multiplication factors $\mathrm{k}_{\text {eff }}$ for both reactor configurations decrease similarly fast 
during burning at the beginning and stabilizes on the value about equal 0.8 after 1000 days of reactor operation $\left(5000 \mathrm{MW}_{\mathrm{th}}\right)$. While the $\mathrm{k}_{\mathrm{eff}}$ for the core loaded solely with $\mathrm{UO}_{2}(2.25 \% \mathrm{U}$ 235) still further slightly decreases, the multiplication factor for the configuration with thorium (Fig.11) does not decrease (self sustaining system).

The concentration of U-233 tends to the saturation value with reactor operation time and sharply increases after cutting off the power (see Figs. 14). In this reactor the saturation concentration of U-233 amounts to about 0.0129 during its work (Fig. 14). During the burning time equal 2500 days only three thorium layers $(30-50 \mathrm{~cm}, 70-90 \mathrm{~cm}$ and $110-130 \mathrm{~cm})$ achieved saturation concentration. The saturation value of U-233 concentration practically does not depend on the power density (Fig. 14). While the kinetics of reaching the saturation value strongly depends on the power density (neutron flux). The higher is the neutron flux the more rapid increase of U-233 concentration is observed (occurs). The five fertile thorium fuel layers alternately located with the uranium dioxide in the fuel rod (see Fig. 11) are irradiated with different neutron flux. The closer is the fertile thorium fuel layer to the center of the reactor core the higher is the neutron flux. The final concentration of U-233 (Fig. 14) consists of two parts: a "power on" concentration and a "power off "one. The total mass (and concentration) of the 'power off' U-233 is equal to the total mass (and concentration) of Pa-233 at the moment of cutting off the power supply.

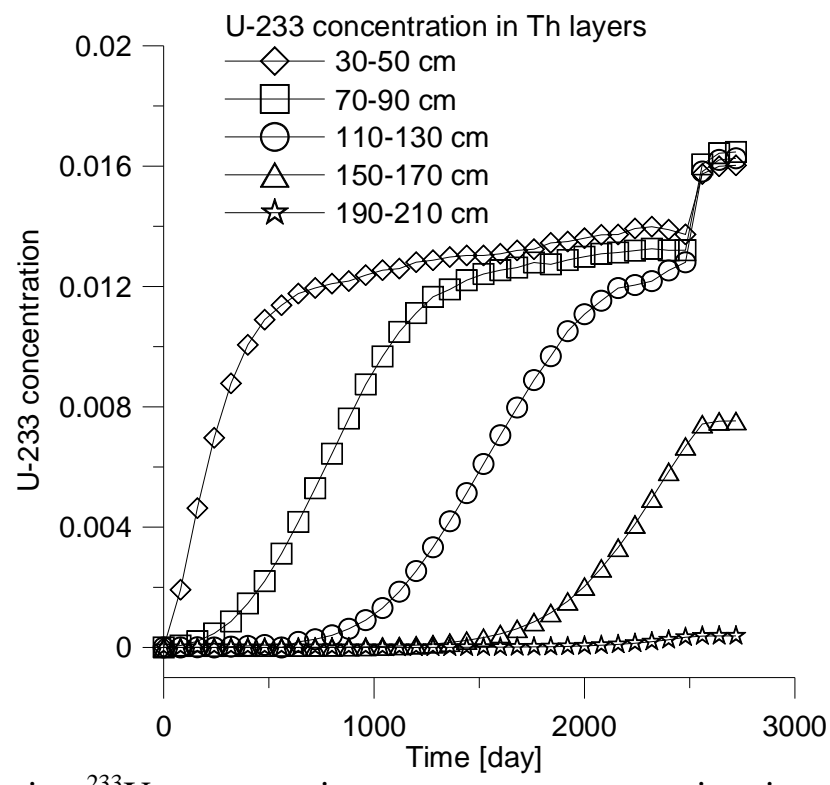

Fig. 14. The uranium ${ }^{233} \mathrm{U}$ concentration versus reactor operation time for five thorium dioxide layers $20 \mathrm{~cm}$ thick as in Fig. 11.

In general, we can infer that the ${ }^{233} \mathrm{U}$ concentration tends to saturation value which does not depend on power density while the kinetics of reaching the saturation value depends on it.

Fig. 15 shows that the concentration of Pa-233 strongly depends on the neutron flux density. The higher is the neutron flux density the more rapid increase of Pa-233 concentration is observed (occurs) and the higher maximum protactinium concentration is reached in function of reactor operation. In this case the protactinium concentration does not reach saturation. Please 
note, that the fixed $5 \mathrm{GW}_{\text {th }}$ power of the reactor (in $\mathrm{U}-\mathrm{Th}$ fuel rods) does not mean the fixed neutron flux density in the $\mathrm{U}-\mathrm{Th}$ rods. The neutron flux density in the rods is relatively complicated function of time and burn-up of thorium.

Initially, the thorium dioxide layers only absorb the neutrons produced in the uranium dioxide layers and after with time of irradiation the thorium layers produce themselves the neutrons due to conversion of fertile thorium into fissile uranium and take on the power load (see Fig. 16) what in turn decreases the neutron flux density. The growing smaller amount of thorium nuclei in function of burn-up influences also on the protactinium concentration. This explains why the protactinium concentration does not tend to the saturation value

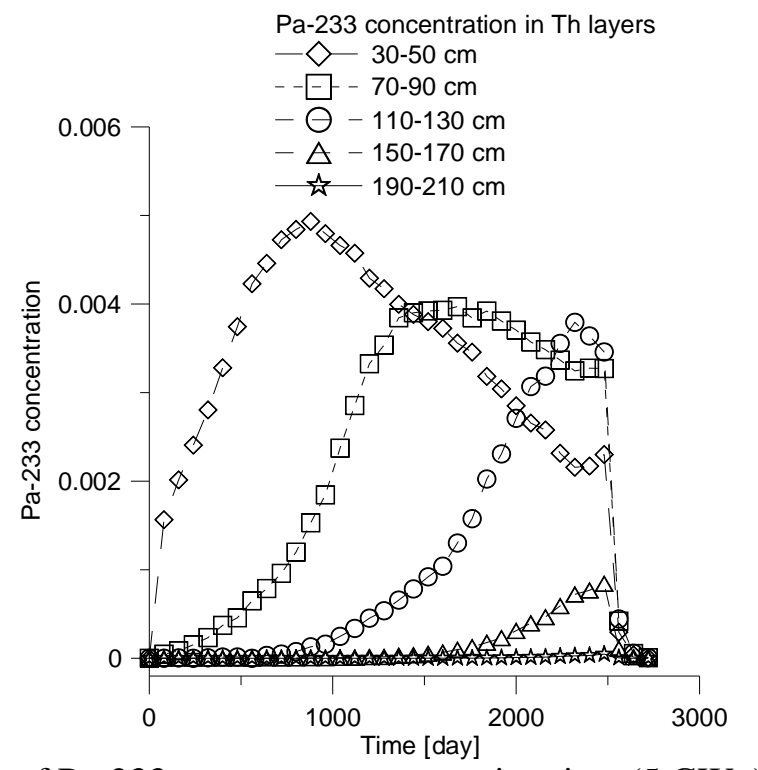

Fig. 15. Concentration of $\mathrm{Pa}-233$ versus reactor operation time $\left(5 \mathrm{GW}_{\mathrm{th}}\right)$ for five thorium dioxide layers $20 \mathrm{~cm}$ thick as in Fig. 11.

In this work the concentration of $\mathrm{Pa}-233$ or $\mathrm{U}-233$ is defined as a relation of the mass of $\mathrm{Pa}$ 233 or U-233 to mass of all actinides in unit of volume.

The time dependence of Pa-233 concentration and U-233 concentration (fig.14 and fig. 15) shows that concentration of $\mathrm{Pa}-233$ and $\mathrm{U}-233$ on the peripheral part of reactor core is very low relative to the center part of core. 


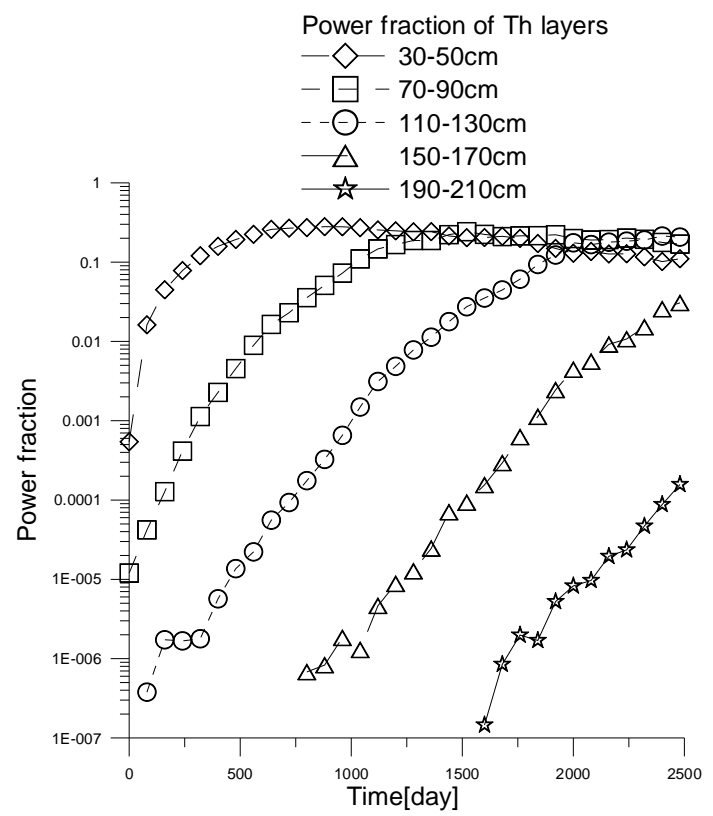

Fig. 16. Power fraction versus reactor operation time $\left(5 \mathrm{GW}_{\mathrm{th}}\right)$ for five thorium dioxide layers $20 \mathrm{~cm}$ thick as in Fig. 11.

In general, we can infer that the ${ }^{233} \mathrm{U}$ concentration tends to saturation value which does not depend on power density while the kinetics of reaching the saturation value depends on it.

The power fraction as a function of reactor operation time on fixed power equal $5 \mathrm{GW}_{\text {th }}$ for five thorium dioxide layers placed in the rods is monotonically increasing function (Fig. 16). After about 1000 days of reactor operation $\left(5000 \mathrm{MW}_{\text {th }}\right)$ the $\mathrm{ThO}_{2}$ power fraction is equal to the power fraction from the $\mathrm{UO}_{2}$ fuel.

\section{Conclusions and remarks}

Conversion of the fertile thorium ${ }^{232} \mathrm{Th}$ into fissile uranium ${ }^{233} \mathrm{U}$ in the peripheral part of the EPR reactor core is ineffective since the neutron flux is comparatively (relatively) small.

For initial concentration of U-233 equal to saturation value (1.29 wt\%) the EPR reactor does not reach criticality, scarcely for $1.5 \mathrm{wt} \%$ the reactor becomes slightly overcritical what permits to exploit the reactor during certain time. This concentration value is a sum of the saturation concentration with the "power off" concentration. It means that once through thorium fuel cycle can be reached with difficulty.

The saturation value of U-233 concentration practically does not depend on the power density. While the kinetics of reaching the saturation value strongly depends on the power density (neutron flux).

Whereas the available neutron numbers for breeding in the thorium-uranium fuel cycle is only a little above zero $(0.1-0.3$, the value is not given precisely in the open literature) we can infer that in the accelerator driven system (ADS) the effect of breeding can be easier utilized in a more flexible way for higher burn-up of the fuel giving impact on economy improvement.

Applying the thorium-uranium fuel cycle the radio-toxicity of the wastes is about three orders of magnitude smaller than in the case of classical PWR reactors. 


\section{References}

[1] B.L. Cohen, The Disposal of Radioactive Wastes from Fission Reactors, Scientific American, June 1977 vol. 236, B. Baggins, There and

[2] Actinide and Fission Product Partitioning and Transmutation. Seventh Information Exchange Meeting Jeju, Republic of Korea 14-16 October 2002

[3] D. Haas: The fuel development programme ADS at ITU; Topical Day on "R\&D activity in support of ADS development held at SCK·CEN - Mol on October $24^{\text {th }} 2000$.

[4] R.A. Jemson, G.P. Lawrence, C.D. Bowman: Accelerator - driven transmutation technology for incinerating radioactive waste and for advanced application to power production; Nucl. Instr. And Methods in Physics Research B68 (1992)474.

[5] S. Wan et al.: Transmutation of ${ }^{239} \mathrm{Pu}$ with spallation neutrons; Journal of Radioanalytical and Nuclear Chemistry, Vol. 247 No 1 (2001) 151 - 157.

[6] Sylvain David, Elisabeth Huffer and Herve Nifenecker; Revisiting the thorium-uranium nuclear fuel cycle; Europhysics News, Volume 38, number 2 (2007) 24 - 27; Article available athttp://www.europhysicsnews.org or http//dx.doi.org/10.1051/EPN:20072007

[7] IAEA; Thorium fuel cycle - Potential benefits and challenges; IAEA-TECDOC-1450, IAEA Vienna May 2005.

[8] Christian Le Brun, Ludovic Mathieu, Daniel Heuer and Alexis Nuttin; Impact of the MSBR concept technology on long-lived radio-toxicant and proliferation resistance; LPSC 0581, document IAEA.

[9] Yu Jiyang, Wang Kan, You Songbo, Jia Baoshan, Shen Shifei, Shi Gong, et al., Thorium Fuel Cycle of a Thorium-based Advanced Nuclear Energy System Progress in Nuclear Energy, Vol. 45, No. 1, pp. 71 - 84, 2004

[10] Permana Sidik, Naoyuki Takaki, Hiroshi Sekimoto, Power density effect on feasibility of water cooled thorium breeder reactor, Progress in Nuclear Energy 50 (2008) 308-313.

[11]A. Lafuente, M. Piera, Exploring new coolants for nuclear breeder reactors, Annals of Nuclear Energy, 37 (2010), 835-844

[12] Chang Joon Jeong, Chang je Park, Won Il Ko, Dynamic Analysis of a thorium fuel cycle in CANDU reactors, Annals of Nuclear Energy 35 (2008) 1842-1848

[13]M. Matsunaka, S. Shido, K. Kondo, H. Miyamaru, I. Murata, Burnup calculation of fusionfission hybrid energy system with thorium cycle Division of Electrical, Electronic and Information Engineering, Graduate School of Engineering, Osaka University, Yamada-oka 2-1, Suita, Osaka 565-0871, Japan,Received 1 August 2006; received in revised form 22 March 2007; accepted 22 March 2007. Available online 7 May 2007

[14] J. Breza, P.Dar`ílek, V. Nec as, Study of thorium advanced fuel cycle utilization in light water reactor VVER-440 Annals of Nuclear Energy, Annals of Nuclear Energy 37 (2010) 685-690

[15]S. Mittag, S. Kliem, Burning plutonium and minimizing radioactive waste in existing PWRs, Annals of Nuclear Energy, Volume 38, Issue 1, January 2011, Pages 98-102 
[16]M. Szuta, A. Wojciechowski; Przyczynek do analizy wykorzystania paliwa na bazie toru $w$ zestawach podkrytycznych sterowanych akceleratorem $i$ w reaktorze EPR, (Contribution to the analysis of thorium based fuel application in the accelerator driven systems and in the EPR reactor).Science Conference, Madralin near Warsaw, Poland, 13 - 14 June 2011

[17] S.Kilim, Basic Data of the EPR Reactor, Raport IEA, B-16, 2009

[18] http://adamswebsearch2.nrc.gov/idmws/ViewDocByAccession.asp?AccessionNumber=ML0924 50764

[19]L. Dąbrowski, M. Szuta; Local structure and cohesive properties of mixed thorium dioxides calculated by "ab initio" method; Nukleonika 2012, 57(1), 101-107.

[20]] Denis B. Pelopowitz, MCNPX - Users manual, LA-CP-05-0369 version 2.6.0, April 2008. https://mcnpx.lanl.gov/ 